\title{
TOPIRAMATE AS ADJUNCTIVE THERAPY TO MANAGE POST-TRAUMATIC MUTILATION IN 3 CATS
}

Alba Troya $^{1^{*}}$, Clare Rusbridge $^{1,2}$, Eirik Kvale $^{1}$

1 Fitzpatrick Referrals, Orthopaedics and Neurology, Surrey, UK 2 University of Surrey, UK

* Now at a different veterinary practice, UK

\section{INTRODUCTION}

Topiramate is a sulfamate-substituted derivative of D-fructose most commonly used as an anti-epileptic drug but with some advocacy for treatment of neuropathic pain. Recently its use has been described in feline hyperaesthesia syndrome and feline ulcerative dermatitis. We describe it for management of suspected post-traumatic neuropathic pain and mutilation in 3 cats.

\section{CASE 1}

DSH, $12 \mathrm{y}, \mathrm{MN}, 4.8 \mathrm{~kg}$, self mutilation of tail stump 8 months after tail pull injury and amputation.

- Hyperalgesia at Cd1-Cd2, lack of pain sensation (Fig. 1).

- Topiramate and pregabalin prescribed.

- Tail stump started healing, moving and having sensation (Fig 2).

- Reducing his medication created bad periods of increasing mutilation. Medication was kept for long term.

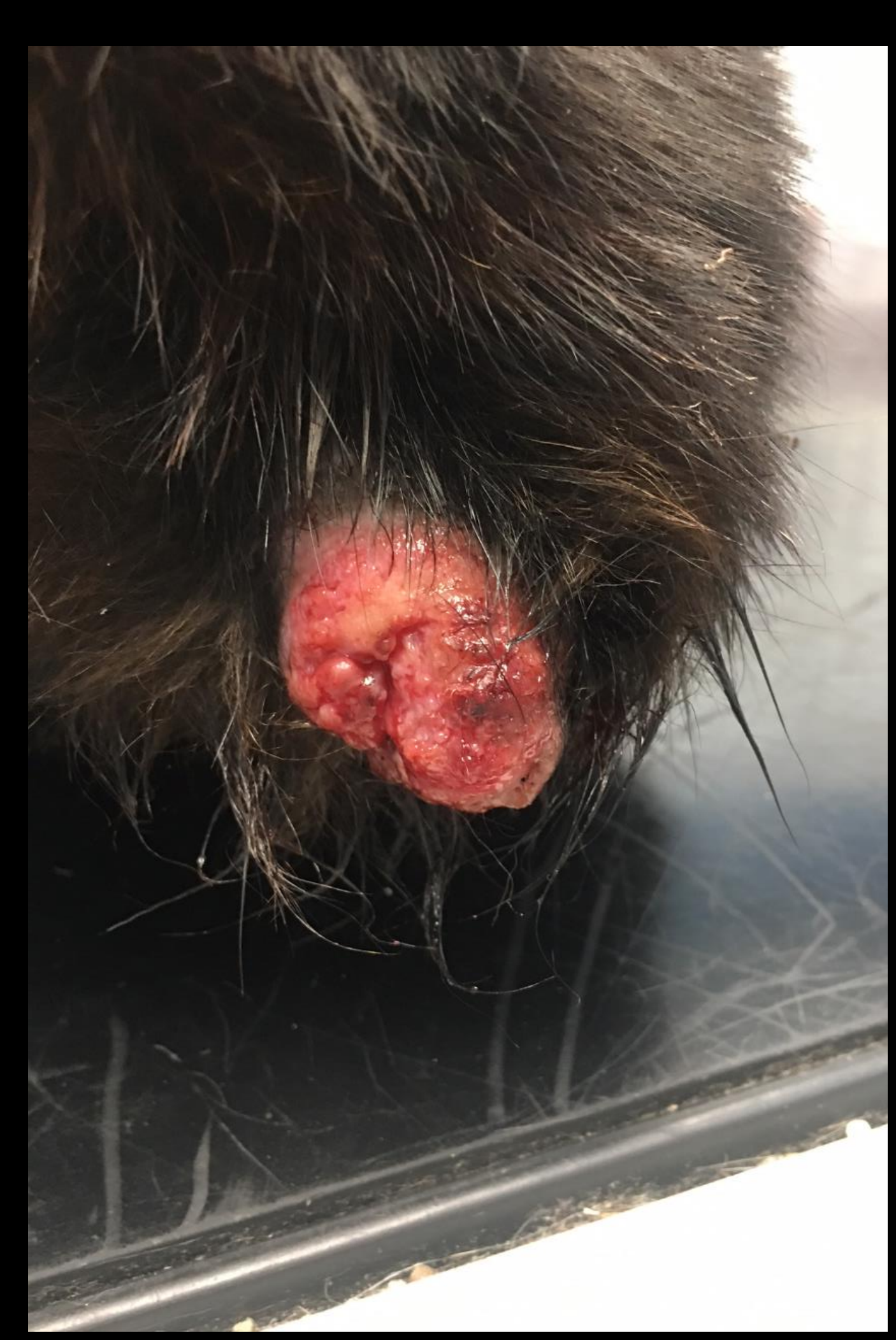

Fig. 1: Tail stump after mutilation in the first referral consult.

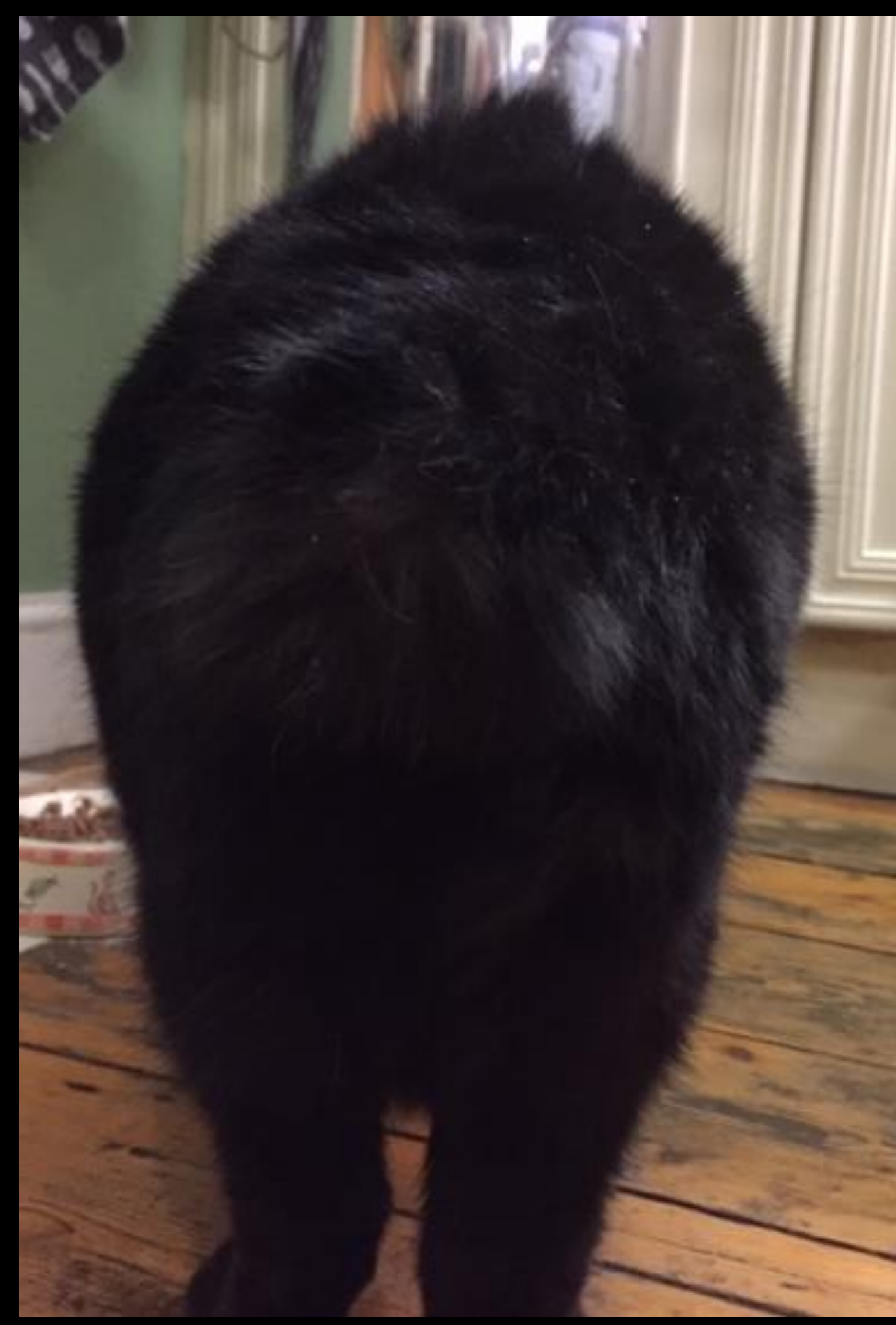

Fig. 2: Tail stump, six months under control.



Fig. 3: Licking lesions on dorsal aspect of toes
Fig. 4: Licking lesions on dorsal aspect of toes

\section{CASE 2}

$\mathrm{BSH}, 5 \mathrm{y}, \mathrm{MN}, 5.5 \mathrm{~kg}$, had left THR and left lateral parapatelar imbrication to resolve a grade 3 medial patellar luxation presenting sciatic neuropraxia after surgery.

- Three months after surgery refers episodes of shaking his leg, chewing his foot until it bleeds and digit 3 chronic hyperextension (Fig 3 and 4).

- Pain on palpation of the sciatic tract was noticed.

- Topiramate, gabapentin and prednisolone were prescribed.

- Four months and a half after treatment owner refers a complete resolution.

\section{CASE 3}

DSH, 3y, MN, 4.8kg, rescued cat presenting tail base and left foot mutilation following pelvic fracture repair (ilial body fracture and sacroiliac luxation). Electromyogram reveal normal velocity for both sciatic nerve, however evidence of denervation potentials (fibrillations and positive sharp wave) in tail head suggesting lesion in the sciatic nerve roots. Pregabalin, topiramate and prednisolone were started. The improvement was evident after 4 months of treatment, topiramate was tapered down until complete withdrawal and pregabalin was kept as long term medication.

\section{RESULT}

The addition of topiramate had a satisfactory outcome in all cats but may have predisposed diarrhoea in Case 3 . Case 1 continued pregabalin and topiramate long term; withdrawal resulted in recurrence of signs. Case 2 and 3 was eventually weaned off all treatment. Post traumatic neuropathic pain and mutilation can be challenging to manage but topiramate may be a useful adjunctive therapy in the cat.

The dose used of topiramate was $5 \mathrm{mg} / \mathrm{kg} \mathrm{q} 12 \mathrm{~h}$ :

In Case 1 (4.8kg) was on $5 \mathrm{mg} / \mathrm{kg}$ topiramate (am) and $10 \mathrm{mg} / \mathrm{kg}$ topiramate $(\mathrm{pm})$ plus $5 \mathrm{mg} / \mathrm{kg}$ pregabalin q12h (topiramate was tapered down to $5 \mathrm{mg} / \mathrm{kg}$ q12h long term plus pregabalin)

In Case 2 (5.5kg) the initial dose was $5 \mathrm{mg} / \mathrm{kg}$ of topiramate q12h, $5 \mathrm{mg} / \mathrm{kg}$ of gabapentin q12h and $1 \mathrm{mg} / \mathrm{kg}$ of prednisolone q24h. All dosages went tapered down until complete withdrawal.

In Case 3 (4.8kg) the initial dose was $5 \mathrm{mg} / \mathrm{kg}$ of topiramate q12h, $5 \mathrm{mg} / \mathrm{kg}$ of pregabalin q12h and $1 \mathrm{mg} / \mathrm{kg}$ of prednisolone q24h. All meds went tapered down until complete withdrawal but pregabalin kept as long term medication. 